\title{
LA VENTA DE LA PLATERÍA EN EL MONASTERIO DE LA ENCARNACIÓN DE OSUNA (1807-1866)
}

\section{THE SALE OF THE SILVERWORK AT THE MONASTERY OF THE INCARNATION IN OSUNA (1807-1866)}

\author{
Antonio Morón CARmona \\ Amigos de los Museos de Osuna. España \\ amoroncarmona@gmail.com
}

\begin{abstract}
Este trabajo es una continuación del publicado en el número anterior de esta revista titulado "La configuración artística del Monasterio de la Encarnación de Osuna en la segunda mitad del siglo XVIII”. Si en aquel se plasmaba su dotación artística, a partir de 1807 las mercedarias padecerán décadas de penurias y carestía que están vinculadas a la coyuntura política que atraviesa España. Por ello se verán obligadas a vender piezas de platería y joyería, destacando las que iban destinadas a sufragar los impuestos solicitados por los invasores franceses ya que, hasta el momento, se desconocen las obras artísticas expoliadas por éstos en Osuna. A finales del siglo XIX, comienza una etapa de holgura que les permitirá la reposición de los enseres que se habían tenido que vender.

Palabras clave: monasterio de la Encarnación; Osuna; penurias; venta; plata.
\end{abstract}

This paper is a continuation of the one published in the previous issue of this journal titled "The Artistic Configuration of the Monastery of the Incarnation in Osuna during the Second Half of the $18^{\text {th }}$ Century". Whereas the aforementioned paper revolved around its artistic endowment, this research focuses on the precarious economic situation at the Monastery from 1807, which underwent economic hardships and a dearth of goods for decades due to the political situation in Spain at the time. Consequently, they were compelled to sell many of the silver objects and jewels they owned, including the ones that were destined to pay the taxes of the French invaders although it remains unknown the works of art that they actually plundered in Osuna. By the end of the $19^{\text {th }}$ century, the economic situation improved, which allowed the replacement of the items that had been sold.

Keywords: Monastery of the Incarnation; Osuna; hardships; sales; silver.

La prosperidad económica que viven las mercedarias descalzas de Osuna en la segunda mitad del siglo XVIII ${ }^{1}$ trocará, desde los primeros años de la

${ }^{1}$ MORÓN CARMONA, Antonio: "La configuración artística del Monasterio de la Encarnación de Osuna en la segunda mitad del siglo XVIII", Laboratorio de Arte, 28, 2016, pp. 283-296. 
siguiente centuria, a una etapa de estrechez que conllevará el cese de las obras de construcción y los encargos artísticos. Su capacidad monetaria se redujo hasta tal punto que se invirtió la tendencia y prueba de ello aparece escrito con la escueta y rotunda frase: "para pago de una deuda y lo restante para subvenir a las urgencias de la comunidad". Así se justificaba entonces la venta de un "plato grande de plata y los dos más chicos, la salvilla, dos macetitas y la copita" en $1807^{2}$. Hasta 1803 se registra la ejecución de obras", por lo que el "pago de una deuda" puede corresponder a las mismas. Este desprendimiento afectó a piezas menores al denominarlas con diminutivos y al describir su tamaño - platos "chicos, macetitas y copita"-, o que no tendrían un uso imprescindible como es una salvilla. Sí aportaría una cuantía más elevada el "plato grande de plata". Esta noticia inaugura otras similares en las que las monjas se ven obligadas a desprenderse de piezas de plata con el fin de afrontar débitos que, como es habitual en sus anotaciones, no se especifica a qué se debían.

Pasados unos años, el 21 de junio de 1813, el padre comendador fray Andrés de San Cristóbal en su visita al monasterio refrendaba una venta más voluminosa y detallada, siendo comendadora sor María Josefa de la Encarnación y sacristana sor María Joaquina de la Merced, exigida por una circunstancia histórica producida unos años antes: "se vendió para pago de la contribución que imponían los señores franceses"4. La ocupación francesa en Osuna-enero de 1810-septiembre de 1812- trajo consigo el pago de desorbitados impuestos que se exigían a toda la población; en el caso de la villa ducal, gran parte de las exacciones llevaban, directa o indirectamente, la firma del mariscal Soult destinadas a la financiación del ejército imperial dependiente de la prefectura de Málaga ${ }^{5}$. Un testimonio de primera mano lo ofrece el cura Antonio María García Blanco, natural de Osuna, uno de los catedráticos fundadores de la Universidad Central de Madrid y diputado en Cortes, quien en sus memorias recordaba cómo unos soldados franceses pasaron un día y una noche en su casa sin parar de comer y beber; al marcharse, obligaron a su familia a darle todo el dinero que tenían y salían con los sables desenvainados en busca de "argent". Las mercedarias descalzas, aparte de afrontar los elevados pagos de los impuestos al igual que el resto de los vecinos, fueron las

${ }^{2}$ Archivo del Monasterio de la Encarnación de Osuna (A.M.E.O.), Libro de Sacristía de 1880, f. 17. Este libro contiene los inventarios de los bienes artísticos, reflejando las donaciones, adquisiciones y ventas desde 1783 a 1909.

3 A.M.E.O., Libro de gastos y recibos. Año 1746. Según arreglo del año 1880. Recibo desde el día 30 de enero de 1746, s. f.

${ }^{4}$ A.M.E.O., Libro de Sacristía..., f. 18. RODRÍGUEZ-BUZÓN, Manuel: Monasterio de la Encarnación-Osuna. Osuna, 1969, s. p.

${ }^{5}$ DÍAZ TORREJÓN, Francisco Luis: Osuna Napoleónica (1810-1812). Sevilla, 2001, pp. 192-263.

${ }^{6}$ GARCÍA BLANCO, Antonio María: Resumen de un siglo. Osuna, 2006, pp. 17-18. 
únicas monjas de Osuna que tuvieron que abandonar su convento y trasladarse al de las dominicas de Santa Catalina, en agosto de 1812, ya que la habilitación de un fuerte en la parte alta del pueblo comprendía los edificios de la Colegiata, la Universidad y de su monasterio de la Encarnación ${ }^{7}$. En la saleta de los Niños de su museo de arte sacro cuelga una carta de hermandad con los santos y escudos de los dominicos y los mercedarios que recuerda este hecho.

La relación de piezas vendidas supone una valiosa información, pues no existe, o no se ha localizado hasta ahora, ningún documento que relacione las obras artísticas perdidas en Osuna ${ }^{8}$. Un caso particular es el del hospital de San Juan de Dios, pues si en un primer momento había sido suprimido como el resto de órdenes religiosas masculinas y sus bienes incautados, por la necesidades sanitarias que tenían las tropas francesas se reabrió y acordó que "las alhajas de la Yglesia estraidas del Hospital de San Juan de Dios se restitullan las que sean necesarias para la Hospitalidad en la celebración el Santo Sacrificio y administración de los Sacramentos"9. En esta excepción se mencionan los ornamentos para la celebración del culto religioso y es lógico pensar que no tendrían gran valor, aunque no se especifican cuáles eran. En el Libro de Sacristía del monasterio de la Encarnación sí se enumeran las que tuvieron que venderse: "quedan de menos de las alhajas de plata las dos lámparas de la iglesia, los cañones de la cruz procesional, los ciriales, el atril, los seis candeleros grandes, la bandera y la vara de Ntro. P. Nolasco, las diademas de San Ramón y San José, el morrión y la rodela de San Miguel, las cuatro palias de los altares. Todo esto se vendió para pago de la contribución que imponían los señores franceses. Más se ha vendido la palangana, dos salvillas una laureda y otra lisa y la confitera onda, el plato y espabiladeras y un peberito chico. Más las perlas de Nuestra Santísima Madre de la Encarnación de la que también se vendió la salamanquesa".

La venta de piezas de plata y de joyería, de gran valor sin duda, es lo que aportaría la cuantía que les ayudaría a cumplir con los impuestos. Esta enajenación afectó principalmente a los atributos de plata de las esculturas que aún hoy reciben culto en el templo: la bandera de San Pedro Nolasco, las diademas de San Ramón Nonato y de San José y el morrión y la rodela de San Miguel Arcángel. Aparte, cabe distinguir entre un grupo de piezas de uso cultual -la cruz procesional con sus ciriales, candeleros, atril, salvillas y las cuatro palias correspondientes a cada uno de los retablos-y otras de uso doméstico -confitera, plato o espabiladeras-. Requiere una mención especial una joya singular: la "salamanquesita de oro esmaltado con un rubí y perlas finas" 10 de la Virgen de la Encarnación. A

7 DÍAZ TORREJÓN, F. L.: Osuna Napoleónica..., op. cit., p. 128.

${ }^{8}$ Ibidem, p. 263.

9 DELGADO ABOZA, Francisco Manuel: La Orden Hospitalaria de San Juan de Dios en Osuna. Osuna, 2013, pp. 270-272.

10 A.M.E.O., Libro de Sacristía..., f. 1v. 
este animal se le atribuía la propiedad de vivir en medio del fuego, sin recibir la menor quemadura, por lo que se le relacionaba con el fuego del Espíritu Santo y completaba adecuadamente la iconografía de la citada advocación. Un ejemplo que nos ayuda a conocer cómo sería esta joya es la salamanquesa que, hoy día, luce en su atuendo la Virgen del Rocío.

No se ha podido averiguar qué cantidad de dinero se exigía en los referidos impuestos de los franceses ni el que reportó la venta de las piezas mencionadas. Sin embargo, con los cañones de la cruz procesional, los ciriales y la vara de San Pedro Nolasco, al ser piezas cilíndricas, puede especularse si se toma como referencia la venta de la vara del simpecado de la Venerable Orden Tercera de Nuestra Señora del Valle de Sevilla. En ese caso, dicha vara estaba compuesta por once cañones y el platero Juan Ruiz tasó cada uno por veinte reales de vellón ${ }^{11}$.

Se sucedieron décadas de precariedad y apuros para las monjas del hábito blanco, acordes con los cambios políticos y económicos que se dan en España tras la retirada de los franceses y el inicio de la implantación del liberalismo. Durante el Trienio Constitucional (1820-1823), el Concejo de Osuna se hallaba endeudado y retomó los planteamientos de la real cédula del 4 de enero de 1814 que permitía la enajenación de las tierras de baldíos y realengos, destinando la mitad a la amortización de los créditos contra el Estado. El cambio de régimen impedirá esta aplicación, por lo que el Ayuntamiento no podrá responder a las deudas contraídas aumentando enormemente, situación de la que se lamentaba en $1845^{12}$.

Ante esta circunstancia desfavorable se registran dos voluminosas ventas en 1824. La primera siendo sor Beatriz María de la Santísima Trinidad sacristana: "el peto, rostrillos y otras alhajas menudas de Nuestra Santísima Madre. Y de la plata de la iglesia se ha vendido la caldereta con su hisopo, los doce candeleros mayores y dos chiquititos, los dos incensarios de los ángeles del trono, una campanilla, una cruz de San Pedro Pascual, una hijuela de plata y siete relicaritos de Nuestra Señora de la Encarnación y unas vinajeras con su plato. Más se vendió el marco de plata de la lámina del coro bajo. Y del Niño Príncipe del Amor un petito de filigrana sobredorado. Se ha vendido más las cuatro macetitas de plata del altar de Nuestra Santísima Madre y las cuatro del tabernáculo, del Niño del facistol y dos lazos de esmeraldas de Nuestra Santísima Madre y una joyita del Niño de la Circuncisión y de la sacristía las dos tacitas y un platito y una campanilla”. La segunda con la nueva comendadora sor María Josefa del Espíritu Santo y sacristana sor María Pastora del Corazón de Jesús: "la custodia más chica

${ }^{11}$ RUIZ BARRERA, María Teresa: "1811: el secuestro de bienes de la VOT de Nuestra Señora del Valle", ASCIL Anuario de Estudios Locales, 6, 2012, p. 83.

12 GAMERO ROJAS, Mercedes: "La tierra en Osuna en el paso del antiguo al nuevo régimen: situación e intentos de reforma", en Osuna entre los tiempos medievales y modernos (siglos XIII-XVIII). Sevilla, 1995, pp. 444-461. 
que había sobredorada, también el jarro de plata y las macetitas de plata vendidas por las urgencias de la comunidad"13.

Este lote de objetos afecta tanto a los de uso litúrgico -caldereta y su hisopo, candeleros de diferentes tamaños, campanitas, otra hijuela más, custodia, jarro- como decorativos -los incensarios que sostendrían unos ángeles no identificados, un marco de plata, las macetas o tibores del altar de la Virgen de la Merced y una "tasita de plata" 14 que tenía el Niño del facistol advocado Príncipe de la Paz-. Ahora aumenta, respecto al anterior, el número de joyas de las que se tienen que desprender. Primeramente, de la Virgen de la Encarnación se venden siete relicarios, de los que se conocían tres: dos de plata y un "relicarito chiquito de plata sobredorada"15. En segundo lugar, especialmente quedó afectado el ajuar de "Nuestra Santísima Madre" de la Merced. De ella se enumeran el peto que sería el "petito de filigrana de plata sobredorada y perlas". Se conoce que tuvo "tres lazos de oro y esmeraldas con sus pendientes y dos joyitas de lo mismo con su lasitos"; además contó con dos rostrillos, uno de "filigrana de plata sobredorada con serco de perlas y un topacio y otro de plata sobredorado"16. Tanto el rostrillo como los lazos pueden identificarse con las piezas que se adquirieron junto a la corona en 1771, que costó 2.366 reales, y los comprados en 1772 por 2.000 reales ${ }^{17}$ respectivamente. Por último, la venta de joyas afectó a otras devociones: una cruz de San Pedro Pascual -escultura que se ubica actualmente en la sala de la Comendadora-, un "petito de filigrana sobredorado" del Niño Jesús Príncipe del Amor y "una joyita del Niño de la Circuncisión”, este último regalo por don Miguel Ortega a la madre sor Margarita de la Natividad, ubicado entonces en el oratorio ${ }^{18}$-hoy denominado Saleta de los Niños- y que las monjas identifican con el Niño Jesús Circuncidado y Príncipe de la Paz del coro bajo.

En 1834 continua la venta de alhajas "de Ntra. Santísima Madre y de la Sra. de la Encarnación"19 y en 1866 se producen las últimas conocidas hasta ahora. Entre tanto, una orden de la Junta del Museo de Sevilla al vicario de Osuna formulada en 1842, solicitaba "la recolección de pinturas de marcado mérito" de los conventos suprimidos en los partidos de Osuna, Marchena y Estepa para ser expuestas en dicho lugar. El sacristán del antiguo convento de agustinos de Nuestra Señora de la Esperanza, obedeciéndola, hizo entrega de los cuadros de San Jerónimo, San Sebastián y San Miguel, hecho que le acarreó su destitución por el secretario de Cámara y Gobierno del arzobispado de Sevilla. El exclaustrado franciscano don

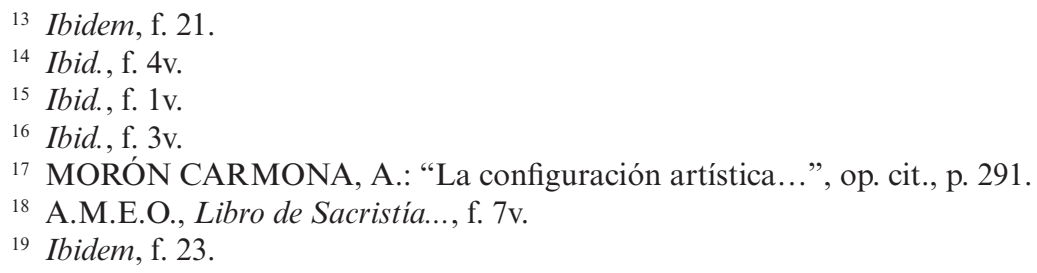


Joaquín Camacho lo sustituyó y, para evitar una diáspora patrimonial, ordenó "que no saliese ni escultura, alhajas, objetos de cultos o pinturas sin orden expresa de la Vicaría", incluyendo los conventos de monjas ${ }^{20}$. La situación que atosigaba a las mercedarias persistía y parece que no acataron dicha orden cuando, en el año 1866, procedieron a la venta de "la cruz procesional, dos candeleros, la vara de Ntro. Padre y la custodia de Sn. Ramón, todo de plata" ${ }^{21}$. Este reducido número de piezas recuerda a la de 1807 , por lo que se intuye una mejora en las arcas del monasterio, y completa a la refrendada en 1813, ya que si entonces se vendió el mástil de la cruz procesional y la diadema de San Ramón, ahora se desprenden de la propia cruz y de la custodia que sostenía San Ramón Nonato en su mano derecha, desapareciendo el ajuar de plata de esta escultura del retablo mayor. Curiosamente, vuelve a repetirse la vara de San Pedro Nolasco, lo que da idea de que la vendida en 1813 se sustituyó por una probablemente adaptada de otra pieza porque, como queda patente, la situación económica no permitía el encargo de una nueva.

Para finalizar estas líneas, es necesario contemplar la nueva etapa política en España a partir de la Constitución de 1876, que en el Ayuntamiento de Osuna se traducirá en el turnismo de alcaldes liberales, conservadores y republicanos ${ }^{22}$. La confesionalidad católica del Estado significó un contexto favorable y las mercedarias se vuelven a embarcar en una serie de adquisiciones que comienzan el mismo año de 1866. Con sor María del Carmen de San Pedro Nolasco y sor María del Carmen de Santa Rita, la última venta coincide con la compra de "seis candeleros, sacras y cruz procesional de metal blanco, la sacras de los cinco altares y el atril del altar mayor". En 1880 se adquieren "dos lámparas de metal blanco, unos ciriales de metal blanco" y, entre 1885 y 1893, un juego de vinajeras, seis candeleros, cuatro blandones de metal blanco por 4.000 reales y "un magnífico frontal de plata rould" ${ }^{23}$ que costó 3.000 reales. También recibieron, por parte de su entonces confesor don Antonio Valderrama, la bandera de San Pedro Nolasco, la custodia y la palma de San Ramón Nonato y seis candeleros de madera dorada. Una dinámica idéntica la protagonizan las carmelitas del monasterio de San Pedro que, a la par de estar inmersas en la reconstrucción de su cenobio entre 1881 y 1883, estaban adquiriendo piezas argénteas: cáliz con la marca NO8DO, vinajeras donadas por doña María del Carmen Alcázar Caballero o la corona de la Virgen del Carmen del coro bajo de Rafael Lecaroz ${ }^{24}$.

${ }^{20}$ CUEVAS SARRIA, Beatriz y MORENO ORTEGA, Rosa: La iglesia del convento de San Agustín de Osuna. Osuna, 2006, pp. 30-31.

${ }^{21}$ A.M.E.O., Libro de Sacristía..., f. 23v.

22 RAMÍREZ OLID, José Manuel: Osuna durante la Restauración I. Osuna, 1999, pp. 288-323.

${ }^{23}$ A.M.E.O., Libro de Sacristía..., f. 27v.

${ }^{24}$ MORÓN CARMONA, Antonio: "Platería y joyería", en Fuga Mundi I. Clausuras de Osuna. El monasterio carmelita de San Pedro. Osuna, 2014, pp. 198-207. 
Las nuevas compras y donaciones tienen una correspondencia directa con las ventas analizadas. Ahora se van a reponer con otras de menor valor, ya que no serán de plata labrada, sino de "metal blanco o plata rould", es decir, metal plateado o alpaca, realizadas a troquel de un modo más industrial que artesanal, de las que se desconocen su autoría. En concreto, los candeleros y los blandones son de estilo neobarroco y alternan superficies lisas con otras decoradas mediante hojas de laurel y hojarascas carnosas, apareciendo en su base en dorado el escudo de la Merced, el anagrama del Ave María y la S atravesada por un clavo, en los candeleros; mientras que en los blandones se reproducen la escena de la anunciación a la Virgen, un cáliz con la Hostia y el referido anagrama. La misma decoración es la que tiene la pareja de lámparas aceiteras que cuelgan de los ángeles lampareros de la capilla mayor. También son de estilo neobarroco las sacras y el atril. Por su parte, el frontal se cubre por una decoración geométrica sobre la que se superponen tres escudos con los mismos motivos que los de los candeleros. Otra solución asequible fue la reposición de los atributos de plata de los santos por piezas simples y toscas de madera dorada. Como resultado, las aureolas de San José, la de San Pedro Nolasco y su banderola, la de San Ramón Nonato junto a su palma y custodia y el morrión y rodela de San Miguel permanecen, de manera desapercibida, como evidencia de las ventas que se hicieron necesarias para pagar los elevados impuestos ordenados por los franceses y para el sostenimiento vital de las mercedarias durante gran parte del siglo XIX.

Fecha de recepción: 30 de septiembre de 2016

Fecha de aceptación: 31 de enero de 2017 


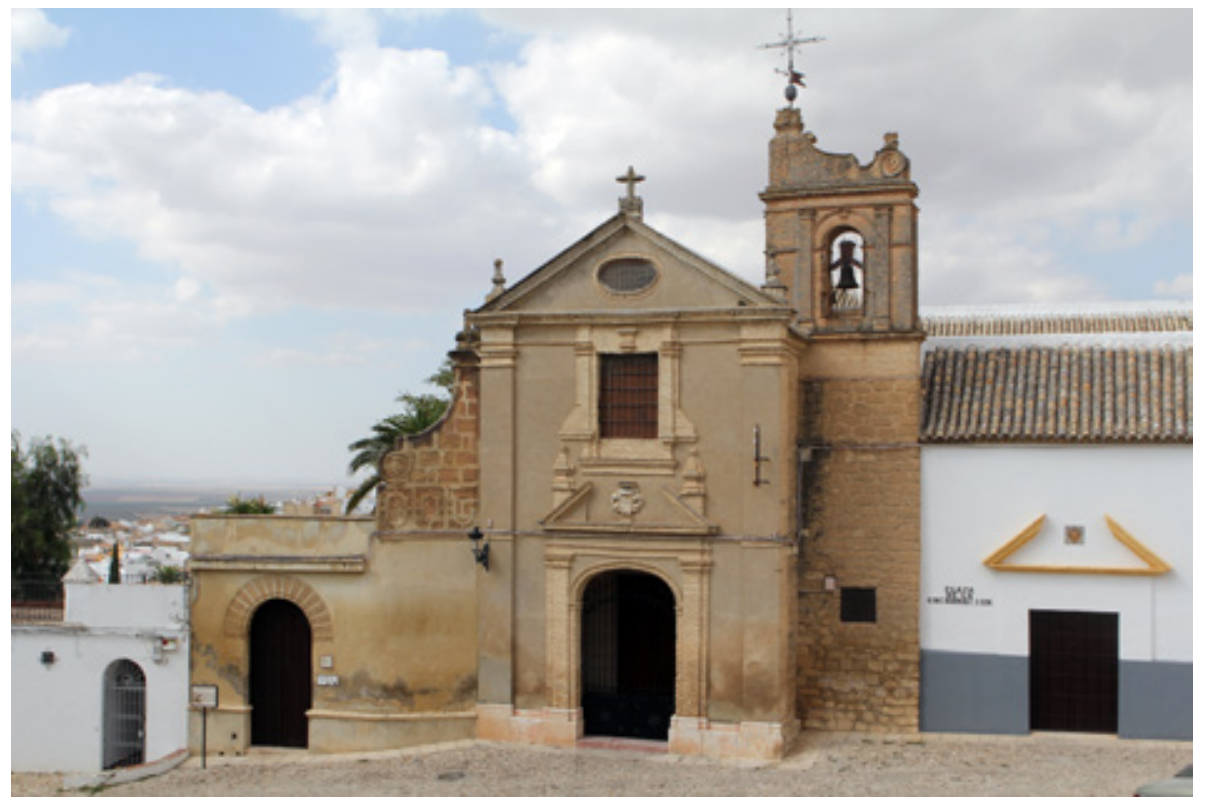

Figura 1. Iglesia del monasterio de la Encarnación de Osuna. 